\title{
GCU
}

Glasgow Caledonian

University

University for the Common Good

\section{Young men who have sex with men's use of social and sexual media and sex-risk associations: cross-sectional, online survey across four countries}

Lorimer, Karen; Flowers, Paul; Davis, Mark; Frankis, Jamie

Published in:

Sexually Transmitted Infections

DOI:

10.1136/sextrans-2015-052209

Publication date:

2016

Document Version

Author accepted manuscript

Link to publication in ResearchOnline

Citation for published version (Harvard):

Lorimer, K, Flowers, P, Davis, M \& Frankis, J 2016, 'Young men who have sex with men's use of social and sexual media and sex-risk associations: cross-sectional, online survey across four countries', Sexually

Transmitted Infections, vol. 92, no. 5, pp. 371-376. https://doi.org/10.1136/sextrans-2015-052209

\section{General rights}

Copyright and moral rights for the publications made accessible in the public portal are retained by the authors and/or other copyright owners and it is a condition of accessing publications that users recognise and abide by the legal requirements associated with these rights.

Take down policy

If you believe that this document breaches copyright please view our takedown policy at https://edshare.gcu.ac.uk/id/eprint/5179 for details

of how to contact us. 


\section{YOUNG MEN WHO HAVE SEX WITH MEN'S USE OF SOCIAL}

\section{AND SEXUAL MEDIA AND SEX RISK ASSOCIATIONS: \\ CROSS-SECTIONAL, ONLINE SURVEY ACROSS FOUR \\ COUNTRIES}

Karen.lorimer@gcu.ac.uk

Glasgow Caledonian University, School of Health \& Life Sciences, Glasgow, UK, G4 0BA

01413318860

Karen Lorimer ${ }^{1}$, Paul Flowers ${ }^{1}$, Mark Davis ${ }^{2}$, Jamie Frankis ${ }^{1}$

1 Glasgow Caledonian University, School of Health \& Life Sciences, Glasgow, G4 0BA

2 Monash University, School of Social Sciences, Victoria 3800, Australia

YMSM use of social and sexual media and sex risks

Key words: Young MSM, online, technologies, HIV prevention 


\section{Abstract \\ Objective}

There has been an increase in new HIV diagnoses among young men who have sex with men (YMSM) over the past decade in both UK and USA contexts, with sex seeking online implicated in driving this development. This study sought to examine YMSM's use of a variety of social and sexual networking websites and 'apps', and assess sexual risk behaviours.

\section{Design}

YMSM were recruited from across four countries in Britain and Ireland, via an online survey using convenience sampling. Data were collected from 2668 men, of whom 702 were aged 1825 years.

\section{Results}

Facebook use was almost ubiquitous and for largely social reasons; sexual media use was common with $52 \%$ using gay sexual networking (GSN) websites frequently and $44 \%$ using similar apps frequently. We found increased odds of high-risk condomless anal intercourse associated with the length of time users had been using GSN websites and lower levels of education. We found no significant differences across the four countries in sexual risk behaviours.

\section{Conclusion}


YMSM are a heterogeneous population with varied sexual health needs. For young men with digital literacy, individual-level online interventions, targeted and tailored, could be directed towards frequent users with lower levels of education. Variation in demographic characteristics of gay sexual networking websites and app users may affect who interventions are likely to reach, depending on where they are targeted. However, interventions, which may catch young men earlier, also provide a major opportunity for reducing sexual health inequalities. 


\section{Introduction}

HIV diagnoses among young men who have sex with men (YMSM) have increased. Two examples show the trend: an 8.7\% increase in the UK 2004-2013; a 34\% increase in the USA between 2006-2009. (HIV in the UK, 2014) [1] A recent study by Beyrer et al. drew upon data from across 15 countries to assess the global epidemiology of HIV, and concluded whilst there was a lack of data on adolescent MSM, what existed suggests young men are a high incidence group. [2] Whilst the literature on the wider MSM population has grown to trial stage, and a meta-analysis has been conducted on the burgeoning evidence base on online sex-seeking and sexual risk behaviours, [3] there remain, in comparison, far fewer studies that focus exclusively on YMSM or disaggregate data to convey clear findings on YMSM. Accordingly, to date the evidence-base in terms of intervention development and trials remains insufficient. [4] Adolescence represents a particularly critical and sensitive phase within the life-course, [5] with families, peers and supportive environments fundamental to adolescent health. [6] Given the circumstances and experiences of YMSM may differ to those of their heterosexual peers or to those of older MSM, it is vital that interventions for YMSM are not simply adaptations of those developed for heterosexual or adult MSM populations. [7]

We reviewed studies that focused on YMSM and found an emerging picture. USA-based studies have, for example, revealed the sex seeking behaviour of YMSM: Winetrobe et al. recruited YMSM ( $\mathrm{n}=146)$ in Los Angeles to explore associations between UAI and partner-seeking behaviours on Grindr (a geosocial networking application geared towards gay, bisexual, and bicurious men), finding higher levels of UAI associated with greater familiarity with the app; [8] Hovarth et al. considered whether YMSM met partners online, offline or both, with the latter 
more likely to report a greater number of sexual partners and UAI. [9] However, this is far from a consistent picture, as other work has shown no association between partners met online and increased sex risks. [10] Issues around the operationalization of sex seeking behavior may be a factor in explaining such conflicting findings. [11] As regards testing behaviours, YMSM appear to test less frequently for HIV than older MSM. [12 13] Yet, YMSM find apps acceptable for interventions, and are willing to engage with prevention efforts via these technologies. [14 15]

The predominance of USA data warrants evidence from other contexts and sub-populations; Intervention development requires an understanding of the transferability of US findings to Europe, the patterning and frequency of digital technology use, and equally understandings of the sub-populations within YMSM who may warrant particular targeting. Finally, this is a rapidly changing field, so even fairly recent studies do not maintain a monopoly on knowledge for long; we need to stay abreast of changing tastes and behaviours for optimising intervention effectiveness.

We conducted a cross-sectional, online survey of YMSM's use of a variety of social and sexual networking media across four countries in Britain and Ireland. We address two key questions here, firstly, describing frequency of, and reasons for using websites and apps. Secondly, we assessed men's sexual risk behaviours and its correlation with use of social and sexual networking websites and apps. Whilst our survey recruited $n=2668$ men aged $18+$ years, overall, this paper focuses on the group ( $\mathrm{n}=702)$ of YMSM (aged 18-25 years). It represents the first study of its kind within Europe to convey data specific to YMSM. 


\section{Methods}

\section{Participants}

We invited MSM resident across Scotland, Wales, Republic of Ireland (ROI) and Northern Ireland (NI) to complete an online survey on their use of various social and sexual networking websites and apps, their sexual behaviours and their views towards the use of websites and apps for HIV prevention. Facebook refused us permission to recruit men from England and so we chose not to recruit English men across all recruitment sites. Pop up message 'blasts' and/or banner adverts were created in order to invited men using gay-specific social media websites (Gaydar, Recon and Squirt), smartphone apps (Grindr and Gaydar) and Facebook to participate via Survey Monkey. For recruitment via Facebook, we sought those who had chosen to 'like' 'LGBT' 'gay' or other such tags. We sought men aged 18+ years, and as Gaydar, Grindr, Squirt and Recon have a minimum user age of 18 , we set this age for the other sites including Facebook. Users located in Scotland, Wales, NI or the ROI were targeted, based on their computer IP addresses or, for smartphone social media, their GPS co-ordinates. Irrespective of which social media people were recruited by, they were all asked the same questions regarding the range of social media they utilized. Recruitment took place between November 2012 and February 2013.

\section{Survey}

The survey link took men to an online information sheet, which provided men with details of the study, the questions, the confidentiality and anonymity assurance. We sought data regarding: participant socio-demographics (age, area of residence, education, sexual orientation, employment, ethnicity, partnership status, living situation); participants' frequency and reasons 
for use of Facebook, gay sexual network (GSN) websites, GSN smartphone apps and barebacking websites/apps (such as www.barebackrt.com); sexual partners in the previous 12 months, whether these were casual partners, knowledge of HIV status of partners, use of condoms, whether seroadaptive strategies had been employed, and details of most recent HIV test and recent STI test.

For social and sexual media use, we defined frequent use as between 'every few days' up to 'all the time'. We computed a high risk sex variable to include men who reported any one of the following three behaviours: condomless anal intercourse (CAI) with two or more partners; CAI with casual partners and/or CAI with HIV status unknown / serodiscordant partners in the previous 12 months. This measure has been used previously in the MRC/CSO Gay Bar Studies. [16] We refer to CAI rather than UAI to reflect the changing context of viral suppression, but note that at the time of writing the drugs used for pre-exposure prophylaxis (PrEP) are not licensed for use in the four countries included in this study. Ethical approval was granted by Glasgow Caledonian University School of Health and Life Sciences Ethics Subcommittee (HLS id: B11/59).

\section{Analysis}

Statistical analyses were conducted in IBM SPSS 21. We sought to undertake two main analyses: firstly, we examined patterns of social and sexual media use by demographic and behavioural characteristics (country, age, highest level of education, sexual identity, partnership status, level of outness and reporting high risk CAI), using the $\chi^{2}$ test; secondly, we used our measure of high risk CAI as a dependent variable to examine differences by various 
demographic and behavioural characteristics (country, age, highest level of education, sexual identity, partnership status, level of outness - given their potential as conceptual confounders), as well as duration and frequency of websites and app use. For this latter analysis, variables significant at the bivariate level $(\mathrm{p}<0.05)$ were included in a multivariate logistic regression model used to estimate odds ratios (OR) and 95\% confidence intervals (CI) for high risk CAI.

\section{Findings}

We recruited 702 YMSM, aged 18-25 years, with a mean age of 21.4 years $(\mathrm{sd}=2.17)$. The majority of YMSM were based in Scotland (47.4\%, $\mathrm{n}=334)$, with $22.4 \%$ ( $\mathrm{n}=158)$ ROI, $15.8 \%$ $(\mathrm{n}=111) \mathrm{NI}$ and $14.3 \%(\mathrm{n}=101)$ Wales. Most identified as white $(95.4 \%, \mathrm{n}=669)$ and reported being HIV negative $(89 \%$. $\mathrm{N}=496)$ with $1.4 \%(\mathrm{n}=8)$ positive and the rest status unknown. Many young men were students $(50.8 \%, \mathrm{n}=356)$ a large minority were employed $(42.2 \%, \mathrm{n}=296)$. The majority identified as gay $(78.8 \%, \mathrm{n}=551)$, with $17.7 \%$ bisexual $(\mathrm{n}=124)$ and $3.4 \%$ straight $(n=24)$. Most were educated to Degree level $(58.5 \%, n=402)$, or further education beyond high school $(35.2 \%, \mathrm{n}=242)$, were single $(71.1 \%, \mathrm{n}=496)$ and out to almost everyone $(68.2 \%, \mathrm{n}=376)$. Most were recruited via the Facebook survey $(33.8 \%, \mathrm{n}=237)$, followed by the Grindr survey $(26.1 \%, \mathrm{n}=183)$ and Gaydar instant message $(24.5 \%, \mathrm{n}=172)$.

\section{Patterns of social and sexual media use}

Table 1 shows the percentage of YMSM who use Facebook, GSN websites, GSN apps and barebacking sites (web or app). Whilst the vast majority $(96.1 \%, \mathrm{n}=667 / 694)$ of YMSM use Facebook, 75.1\% (493/656) use GSN websites, 60.4\% (n=373/618) use GSN apps and 10.1\% $(\mathrm{n}=61 / 601)$ use barebacking sites. The frequency of use of these sites varied, with more YMSM 
using the GSN websites frequently $(55.6 \%, \mathrm{n}=365 / 656)$, compared to apps $(50.5 \%, \mathrm{n}=312 / 618)$, but fewer used these frequently compared to Facebook $(92.1 \%, n=639 / 694)$. The majority of YMSM do not use barebacking sites, although 5.8\% $(n=35 / 601)$ use them frequently. Figure 1 shows the pattern of use of social and sexual media.

Table 1: Frequency of use of Facebook and gay sexual networking websites and apps

\begin{tabular}{|c|c|c|c|c|}
\hline & $\begin{array}{l}\text { Facebook } \\
\%(n / 694)\end{array}$ & $\begin{array}{l}\text { GSN websites } \\
\%(n / 656)\end{array}$ & $\begin{array}{c}\text { GSN } \\
\text { apps } \\
\%(\mathrm{n} / 618) \\
\end{array}$ & $\begin{array}{c}\text { Barebacking } \\
\text { sites } \\
\%(\mathrm{n} / 601) \\
\end{array}$ \\
\hline $\begin{array}{l}\text { Have never used, or } \\
\text { stopped using }\end{array}$ & $3.9(27)$ & $24.8(163)$ & $39.6(245)$ & $89.9(540)$ \\
\hline Infrequent use & $4.0(28)$ & $19.5(128)$ & $9.9(61)$ & $4.3(26)$ \\
\hline \multirow[t]{2}{*}{ Frequent use } & 92.1 (639) & $55.6(365)$ & $50.5(312)$ & $5.8(35)$ \\
\hline & $\%(n / 667)$ & $\%(n / 493)$ & $\%(n / 373)$ & $\%(n / 61)$ \\
\hline $\begin{array}{l}\text { Every few months or } \\
\text { longer }\end{array}$ & $0.7(5)$ & $5.5(27)$ & $4.8(18)$ & $18.0(11)$ \\
\hline About once per month & $1.2(8)$ & $7.1(35)$ & $5.1(19)$ & $9.8(6)$ \\
\hline About once per week & $2.2(15)$ & $13.4(66)$ & $6.4(24)$ & $4.8(9)$ \\
\hline Every few days & $8.2(55)$ & 31.0 (153) & $21.1(75)$ & $21.3(13)$ \\
\hline At least once per day & 22.3 (149) & 24.1 (119) & $23.6(88)$ & $9.8(6)$ \\
\hline Several times per day & 33.7 (225) & $10.1(50)$ & $23.1(86)$ & $4.9(3)$ \\
\hline All the time & $31.5(210)$ & $8.7(43)$ & $16.9(63)$ & $21.3(13)$ \\
\hline
\end{tabular}


Table 2: Reasons for using Facebook, GSN websites, GSN apps and barebacking sites

\begin{tabular}{|c|c|c|c|c|}
\hline & $\begin{array}{l}\text { Facebook } \\
\%(n / 667)\end{array}$ & $\begin{array}{l}\text { GSN websites } \\
\%(n / 493)\end{array}$ & $\begin{array}{l}\text { GSN apps } \\
\%(n / 373)\end{array}$ & $\begin{array}{l}\text { Barebacking } \\
\text { websites or apps } \\
\%(n / 61)\end{array}$ \\
\hline Social networking & $83.4(556)$ & $37.3(184)$ & $31.1(116)$ & $4.9(3)$ \\
\hline To update my status & $57.1(381)$ & $3.2(16)$ & $3.8(14)$ & $4.9(3)$ \\
\hline To check family/friends' status & $71.1(474)$ & $3.7(18)$ & $3.5(13)$ & $4.9(3)$ \\
\hline Chat to friends/family & $79.2(528)$ & $10.3(51)$ & $15.5(58)$ & $4.9(3)$ \\
\hline To post/view photos & $67.8(452)$ & $3.2(16)$ & $2.1(8)$ & $6.6(4)$ \\
\hline To make new friends & $20.7(138)$ & $31.8(157)$ & $34.6(129)$ & $4.9(3)$ \\
\hline To reconnect with old friends & $45.7(305)$ & $3.0(15)$ & $4.8(18)$ & $3.3(2)$ \\
\hline To arrange social events/meet new friends & $60.4(403)$ & $3.9(19)$ & $3.8(14)$ & $1.6(1)$ \\
\hline Arrange other group activities (e.g. sports, & $34.6(231)$ & $1.8(9)$ & $2.4(9)$ & $1.6(1)$ \\
\hline To access support & $2.4(16)$ & $3.7(18)$ & $3.2(12)$ & $1.6(1)$ \\
\hline To connect with the gay community & $11.1(74)$ & $34.7(171)$ & $32.2(120)$ & $6.6(4)$ \\
\hline To look for a boyfriend & $7.0(47)$ & $45.8(226)$ & $48.5(181)$ & $8.2(5)$ \\
\hline Meet guys for dates & $6.0(40)$ & $52.1(257)$ & $56.0(209)$ & $14.8(9)$ \\
\hline Cyber sex (swap horny messages) & $5.8(39)$ & $37.7(186)$ & $40.2(150)$ & $18.0(11)$ \\
\hline Swap naked pictures & $3.0(20)$ & $43.8(216)$ & $50.7(189)$ & $23.0(14)$ \\
\hline Webcam sex & $2.5(17)$ & $25.2(124)$ & $14.7(55)$ & $11.5(7)$ \\
\hline Meet guys for sex & $3.9(26)$ & $61.9(305)$ & $61.4(229)$ & $39.3(24)$ \\
\hline To look for bareback sex & $1.5(10)$ & $9.1(45)$ & $8.6(32)$ & $36.1(22)$ \\
\hline To arrange sex when I am travelling/away & $2.7(18)$ & $29.8(147)$ & $29.2(109)$ & $13.1(8)$ \\
\hline Access sexual health information & $1.3(9)$ & $3.9(19)$ & $2.4(9)$ & $1.6(1)$ \\
\hline To kill time & $59.2(395)$ & $45.4(224)$ & $51.5(192)$ & $13.1(8)$ \\
\hline
\end{tabular}

Bold: indicates 1 of the 3 most common responses in each column 
The reasons men provided for their Facebook and their GSN website and app use are shown in Table 2. Common Facebook use reasons were: social networking, chatting to family/friends and to check family/friends' status. Reasons for using GSN websites were: meeting guys for sex, to kill time and to meet guys for dates. Reasons for using GSN apps were: meeting guys for sex, to kill time and to swap naked pictures. Barebacking site use was for: meeting guys for sex, to look for bareback sex and to swap naked pictures. Thus, sites such as Facebook are used for social and GSN websites and apps used for sexual reasons; however, a substantial proportion of men are using them simply to 'kill time'.

Several demographic and behavioural factors were associated with being a frequent user of Facebook, GSN websites and apps, shown in table 3. These univariate analyses found that frequent Facebook use was significantly associated with being out to all and using the gay scene; frequent use of GSN websites was associated with being unemployed or on sickness benefit (a government benefit for disability or ill health), higher levels of educational attainment, being single, not being 'out', and; frequent use of GSN apps was associated with country of residence (Wales), employment (employed/self-employed), highest qualification (secondary/high school), being single, being gay identifying, having ever had an HIV test and use of the gay scene. 
Table 3: Demographic and behavioural characteristics of the sample and comparisons of frequent social and sexual networking use

\begin{tabular}{|c|c|c|c|c|c|c|}
\hline & $\begin{array}{c}\text { Facebook use } \\
\%(\mathrm{n})\end{array}$ & $\begin{array}{c}\text { Chi2 } \\
\text { P Value }\end{array}$ & $\begin{array}{c}\text { GSN websites } \\
\%(\mathrm{n})\end{array}$ & $\begin{array}{c}\text { Chi2 } \\
\text { P Value }\end{array}$ & $\begin{array}{c}\text { GSN apps } \\
\%(\mathrm{n})\end{array}$ & $\begin{array}{c}\text { Chi2 } \\
\text { P Value }\end{array}$ \\
\hline \multicolumn{7}{|l|}{ Country } \\
\hline Scotland & $91.5(303 / 331)$ & \multirow[t]{4}{*}{0.315} & $52.1(162 / 311)$ & \multirow[t]{4}{*}{0.069} & $51.5(152 / 295)$ & \multirow[t]{4}{*}{$<0.001$} \\
\hline Wales & $91.1(92 / 101)$ & & $67.4(64 / 95)$ & & $70.5(62 / 88)$ & \\
\hline Northern Ireland & $89.7(96 / 107)$ & & $57.3(59 / 103)$ & & $51.6(49 / 95)$ & \\
\hline Republic of Ireland & $95.5(148 / 155)$ & & $54.4(80 / 147)$ & & $35.0(49 / 140)$ & \\
\hline \multicolumn{7}{|l|}{ Employment } \\
\hline Employed/self-employed & $940.1(264 / 293)$ & \multirow[t]{3}{*}{0.257} & $60.8(166 / 273)$ & \multirow[t]{3}{*}{0.002} & $58.4(150 / 257)$ & \multirow[t]{3}{*}{0.003} \\
\hline Unemployed/carer/sickness* & $93.9(46 / 49)$ & & $70.8(34 / 48)$ & & $50.0(23 / 46)$ & \\
\hline Student & $93.5(329 / 352)$ & & $49.3(165 / 335)$ & & $44.1(139 / 315)$ & \\
\hline \multicolumn{7}{|l|}{ Highest qualification } \\
\hline Secondary school & $97.7(42 / 43)$ & \multirow[t]{3}{*}{0.381} & $67.4(29 / 43)$ & \multirow[t]{3}{*}{0.042} & $57.1(24 / 42)$ & \multirow[t]{3}{*}{0.006} \\
\hline Further education & $91.6(219 / 239)$ & & $49.8(113 / 227)$ & & $42.1(90 / 214)$ & \\
\hline Degree/postgraduate & $92.0(367 / 399)$ & & $57.9(217 / 375)$ & & $5.6(195 / 351)$ & \\
\hline \multicolumn{7}{|l|}{ In a relationship } \\
\hline Yes & $93.0(160 / 172)$ & \multirow[t]{2}{*}{0.735} & $38.8(64 / 165)$ & \multirow[t]{2}{*}{$<0.001$} & $36.1(57 / 158)$ & \multirow[t]{2}{*}{$<0.001$} \\
\hline No & $92.2(451 / 489)$ & & $63.3(292 / 461)$ & & $57.4(249 / 434)$ & \\
\hline \multicolumn{7}{|l|}{ Sexual orientation } \\
\hline Gay & $92.9(507 / 546)$ & \multirow[t]{2}{*}{0.130} & $56.7(293 / 517)$ & \multirow[t]{2}{*}{0.310} & $54.3(265 / 488)$ & \multirow[t]{2}{*}{$<0.001$} \\
\hline Non-gay identifying & $89.0(130 / 146)$ & & $51.8(71 / 137)$ & & $36.7(47 / 128)$ & \\
\hline \multicolumn{7}{|l|}{ How out } \\
\hline Out to all & $94.1(353 / 375)$ & \multirow[t]{2}{*}{0.007} & $52.9(198 / 374)$ & \multirow[t]{2}{*}{0.015} & $54.0(202 / 374)$ & \multirow[t]{2}{*}{0.091} \\
\hline Not out & $87.4(153 / 175)$ & & $64.0(112 / 175)$ & & $46.3(81 / 175)$ & \\
\hline \multicolumn{7}{|l|}{ Ever had an HIV test } \\
\hline Yes & $92.7(279 / 301)$ & \multirow[t]{2}{*}{0.448} & $56.0(169 / 302)$ & \multirow[t]{2}{*}{0.987} & $56.0(168 / 300)$ & \multirow[t]{2}{*}{0.011} \\
\hline No & $90.9(241 / 265)$ & & $55.9(147 / 263)$ & & $45.3(120 / 265)$ & \\
\hline \multicolumn{7}{|l|}{ Ever use the gay scene } \\
\hline Yes & $94.6(316 / 334)$ & \multirow[t]{2}{*}{0.008} & $57.5(191 / 332)$ & \multirow[t]{2}{*}{0.474} & $55.6(185 / 333)$ & 0.019 \\
\hline Never & $88.3(189 / 214)$ & & $54.4(117 / 215)$ & & $45.3(97 / 214)$ & \\
\hline
\end{tabular}

GSN: gay social networking; * Grouped to capture those on a government benefit for unemployment, or sickness, or ill health. 


\section{Sex risk associations with use of GSN websites and apps}

As to our second main question for this work, we assessed men's sexual risk behaviours and correlations with use of social and sexual networking websites and apps. Regarding testing behaviours, overall, just over half $(53.3 \%, 302 / 567)$ of young MSM had ever had a HIV test. Of those, $82.1 \%$ (248/302) reported having one in the past year. Almost half $(45.8 \%, 257 / 561)$ had never had a STI test, whilst $44.2 \%(248 / 561)$ reported having had a STI test in the past year, of whom 12.8\% (72/562) reported a STI. Regarding comdomless anal intercourse, just under half $(48.5 \%, 275 / 567)$ reported CAI in the past 12 months. Of these YMSM, 32.4\% (88/272) reported CAI always with a casual partner, 29.8\% (81/272) sometimes and 37.9\% (103/272) never with a casual partner. Using our measure of 'high risk sex', we found 39.4\% (104/264) of the group who reported CAI in the past 12 months fell into the high risk category. As such, around 1 in 7 YMSM in this sample had high risk CAI in the past 12 months with a similar proportion for casual partnering.

We sought to examine the associations with high risk CAI, but found no association between our high risk CAI variable and country, employment, sexual orientation or length of time using the GSN apps. However, being a frequent user of GSN websites was significantly associated with reporting high risk $\mathrm{CAI}$ ( $\chi^{2}{ }_{1}=8.79 ; P=0.003$ ), as was using GSN websites for a longer duration (with increasing length of time associated with increased risk of CAI) ( $\left.\chi^{2}{ }_{5}=19.14 ; P=0.002\right)$, being educated to high school level rather than degree or postgraduate $\left(\chi_{2}^{2}=12.32 ; P=0.002\right)$ and having a partner rather than being single ( $\left.\chi^{2}{ }_{1}=6.76 ; P=0.009\right)$. 
Based on these bivariate results, a multivariable logistic regression model examined associations with high-risk CAI, including the significant variables: education, duration of GSN website use, frequency of GSN website use, and partner type. We found lower levels of education (i.e., high school only) associated with increased odds of high risk CAI (OR 3.1, 95\% CI 1.5-6.9; $P=0.002)$. There were also increased odds of high risk CAI by the length of time using GSN websites, with users of $1-5$ years being 2.4 times (OR 2.4, 95\% CI 1.3-4.1; $P=0.005$ ), and those using the sites for more than 5 years 3.1 times (OR 3.1, 95\% CI 1.5-6.1; $P=0.001$ ), more likely to report high risk CAI than new users $(<1$ year). Frequent users of GSN websites were also 1.7 times more likely to report high risk CAI than infrequent/non-users (OR 1.7, 95\% CI 1.0-2.9; $P=0.039$ ), but relationships status was not related to high risk CAI.

\section{Discussion}

This study examined YMSM's use of social and sexual media and sexual risk behaviours and sought to determine sex risk associations with use of GSN websites and apps. A majority of YMSM were frequent users of Facebook, and 52\% used GSN websites and 44\% used GSN apps every few days or more. We found several demographic and behavioural factors were associated with frequent use, including how 'out' men were, their employment status, their level of education and whether they were in a relationship. We did not find country-level differences, indicating similar patterns of use across the four countries. Overall, these young men favoured GSN apps, but those who were non-gay identifying were more likely to use GSN websites. We found increased odds of CAI associated with the length of time users had been using GSN websites and lower levels of education. Overall, around 1 in 7 YMSM had high risk CAI in the 
past 12 months, and 1 in 7 had CAI with a casual partner. We found no significant differences across the four countries in sexual risk behaviours.

For those seeking to develop interventions targeting YMSM in general, our data may be helpful as it illuminates who may be found amidst the plethora of sites. It is worth considering that YMSM are regular users of both GSN websites and apps, with daily use of websites and apps being common; as such, there may be opportunities to layer health promotion over time, offer higher doses of intervention, or boost intervention components. However, if young men who engage in high-risk CAI are sought, then targeting GSN websites may be advantageous, as our findings suggest it is here you are likely to find more of these particular young men.

Nevertheless, we should also bear in mind the effectiveness of even brief interventions delivered online, particularly if they are theoretically based. [17 18] Of note, our findings do not indicate a causal relationship between duration, or frequency, of use of GSN websites and high risk CAI; however, they do suggest the viability of exploring the targeting of frequent and longer users of GSN websites who are at elevated risk of HIV transmission and enable complex intervention designs facilitated by the delivery of multiple and synergistic intervention doses.

The association with lower levels of education and increased GSN website use as well as with high risk CAI highlights inequalities within sexual health and the importance of understanding MSM as a heterogeneous population with varied sexual health needs; they are suggestive of a range of intervention opportunities. Our finding that around half of YMSM use gay social networking websites and apps simply to browse and kill time is similar to other work, [14] and suggests an opportunity for more intensive or interactive HIV risk reduction interventions. For 
example, individual level, targeted and tailored, on-line gaming interventions may be worthy of exploration. Our findings suggest these could be targeted towards the population of frequent users with lower levels of education attainment who by their participation within this study do not lack digital literacy. Previous studies have shown the importance of paying attention to retention within internet-based studies, [19] but also that it is possible to engage a range of YMSM, [7] so it remains vital to ensure the best approaches are trialled and are appropriate for different populations.

Mustanski et al. reviewed the epidemiological literature on factors associated with sexual risk among YMSM, highlighting the importance of exploring multiple factors across micro and macro-systems, due to the importance of not only personal-level factors but also relationship and family factors as well as sociosexual context in sexual risks. [10] It may well be more effective (given that sex is not an individual behavior) to target wider communities of YMSM. Given our data, along with others, reveal sex-risk behaviours among adolescent MSM, there is a case for earlier intervention to occur, whether online, offline or both. Intervening earlier points towards settings such as schools, not just to affect proximal but also distal factors, which the Mustanski et al (2011) paper highlight. This could be a further opportunity for research to explore the feasibility of online interventions in partnership with school curriculums, certainly around the areas of knowledge improvement and reduced risk behaviours but also the culture that may inhibit positive behaviours. Although caution is warranted given the limitations of untargeted sex and relationships education, [20] and educators being able, whether through supportive curriculum, policies and training, to deliver sexual orientation and gender identity topics - as the Ontario, Canada experience revealed can be challenging. [21] 
Limitations to this study include the cross-sectional nature, which by design prohibits us from inferring causality, and the convenience sampling prohibits generalisability to a wider population or other populations of YMSM. Strengths include the multi-country comparison, even though few differences were found, perhaps indicating a similar culture of use by YMSM across these contexts. We also recruited across multiple-sites and apps and enquired about a range of use rather than focusing on one, as some studies have done. In the absence of UK-based data explicitly focusing on YMSM, this study provides an important contemporary snapshot of the patterning of YMSM's use of gay social and sexual networking websites and apps. The patterns of young men's use of social and sexual media, revealing who may be using what, when and why, can direct future research and health promotion in these contexts.

\section{Key messages:}

- YMSM were frequent users of gay sexual networking websites and apps, with many using them daily or every few days.

- Variation in demographic characteristics of gay sexual networking websites and app users may affect who interventions are likely to reach, depending on where they are targeted.

- Risk for HIV transmission increased with the length of time YMSM reported having used gay sexual networking websites, and the frequency of their use. 


\section{Acknowledgements}

KL, PF and JF are funded by Glasgow Caledonian University; MD is funded by Monash University. We thank the organisations that helped with recruitment and the men who agreed to take part in the survey. We also thank the three anonymous reviewers of the manuscript.

\section{Contributors}

KL helped to design the study, carried out the analysis, wrote the first draft of the manuscript and led revisions. PF and MD helped to design the study and helped to draft the manuscript. JF designed the study, carried out some of the data analysis and helped to draft the manuscript. All authors read and approved the final manuscript.

\section{References}

1. Prejean J, Song R, Hernandez A, et al. Estimated HIV Incidence in the United States, 20062009. PLOS One 2011;6(8):e17502.

2. Beyrer C, Baral SD, van Griensven F, et al. Global epidemiology of HIV infection in men who have sex with men. The Lancet 2012;380(9839):367-77

3. Liau A, Millett G, Marks G. Meta-analytic examination of online sex-seeking and sexual risk behavior among men who have sex with men. Sex Transm Dis 2006;33(9):576-84

4. Mustanski BS, Newcomb ME, Du Bois SN, Garcia SC, Grov C. HIV in young men who have sex with men: a review of epidemiology, risk and protective factors, and interventions. Journal of sex research 2011;48(2-3):218-53

5. Due P, Krølner R, Rasmussen M, et al. Pathways and mechanisms in adolescence contribute to adult health inequalities. Scandinavian Journal of Public Health 2011;39(6 suppl):62-78

6. Viner RM, Ozer EM, Denny S, et al. Adolescence and the social determinants of health. The Lancet 2012;379(9526):1641-52

7. Mustanski B, Garofalo R, Monahan C, Gratzer B, Andrews R. Feasibility, Acceptability, and Preliminary Efficacy of an Online HIV Prevention Program for Diverse Young Men who have Sex with Men: The Keep It Up! Intervention. AIDS and Behavior 2013:1-14

8. Winetrobe H, Rice E, Bauermeister J, Petering R, Holloway IW. Associations of unprotected anal intercourse with Grindr-met partners among Grindr-using young men who have sex with men in Los Angeles. AIDS Care 2014;26(10):1303-08

9. Horvath KJ, Rosser BRS, Remafedi G. Sexual Risk Taking Among Young Internet-Using Men Who Have Sex With Men. American Journal of Public Health 2008;98(6):1059-67

10. Mustanski B, Newcomb ME, Clerkin EM. Relationship characteristics and sexual risk-taking in young men who have sex with men. Health Psychology 2011; 30(5). 
11. Abara W, Annang L, Spencer SM, Fairchild AJ, Billings D. Understanding internet sexseeking behaviour and sexual risk among young men who have sex with men: evidences from a cross-sectional study. Sexually Transmitted Infections 2014;90(8):596-601

12. Berg RC. Predictors of never testing for HIV among a national online sample of men who have sex with men in Norway. Scandinavian Journal of Public Health 2013;41(4):398404

13. Holt M, Rawstorne P, Wilkinson J, Worth H, Bittman M, Kippax S. HIV Testing, Gay Community Involvement and Internet USE: Social and Behavioural Correlates of HIV Testing Among Australian Men Who have Sex with Men. AIDS and Behavior 2012;16(1):13-22

14. Holloway I, Rice E, Gibbs J, Winetrobe H, Dunlap S, Rhoades H. Acceptability of Smartphone Application-Based HIV Prevention Among Young Men Who Have Sex With Men. AIDS and Behavior 2014;18(2):285-96

15. Burrell E, Pines H, Robbie E, et al. Use of the Location-Based Social Networking Application GRINDR as a Recruitment Tool in Rectal Microbicide Development Research. AIDS and Behavior 2012;16(7):1816-20

16. Wallace LA, Li J, McDaid L. HIV Prevalence and Undiagnosed Infection among a Community Sample of Gay and Bisexual Men in Scotland, 2005-2011: Implications for HIV Testing Policy and Prevention. . PLoS One 2014;9(e90805)

17. Hirshfield S, Chiasson MA, Joseph H, et al. An online randomized controlled trial evaluating HIV prevention digital media interventions for men who have sex with men. PLoS One 2012;7(10):e46252-e52

18. Kiene SM, Barta WD. A Brief Individualized Computer-Delivered Sexual Risk Reduction Intervention Increases HIV/AIDS Preventive Behavior. Journal of Adolescent Health 2006;39(3):404-10

19. Bull SS, Vallejos D, Levine D, Ortiz C. Improving recruitment and retention for an online randomized controlled trial: experience from the Youthnet study. AIDS Care 2008;20(8):887-93

20. Elliott L, Henderson M, Nixon C, Wight D. Has untargeted sexual health promotion for young people reached its limit? A quasi-experimental study. Journal of Epidemiology and Community Health 2013 doi: 10.1136/jech-2012-201034

21. Shipley H. Religious and sexual orientation intersections in education and media: A Canadian perspective. Sexualities 2014;17(5-6):512-28 
The Corresponding Author has the right to grant on behalf of all authors and does grant on behalf of all authors, an exclusive licence (or non-exclusive for government employees) on a worldwide basis to the BMJ and co-owners or contracting owning societies (where published by the BMJ on their behalf), and its Licensees to permit this article (if accepted) to be published in Sexually Transmitted Infections and any other BMJ products and to exploit all subsidiary rights, as set out in our licence.

Competing Interest: None declared 


\section{Figure legends}

Figure 1: Frequency of Facebook, GSN website and GSN app use (\%) 